can be applied to normal metallographic microscopes. A further advantage of the apparatus described is that it can be used during ordinary examination of metallographic specimens.

E. M. H. Lips. J. SACK.

Natuurkundig Laboratorium

der N. V. Philips' Gloeilampenf zbrieken, Eindhoven.

June 2.

${ }^{1}$ Bierbaum, "The Microcharacter", Trans. American Society for Steel Treating, 18, 1009 (1930). Gillet, "Properties of Ferrite as
Revealed by Scratch Hardness Tests", Metals and Alloys 5, 159 (1934).

\section{Measurements of Noise}

Those interested in noise measurement will be aware that a new unit of equivalent loudness, the British Standard Phon, has been introduced by the British Standards Institution (Glossary of Acoustical Terms and Definitions B.S. 661-1936). The standard of reference is a plane sound wave of 1,000 cycles per sec., heard alternately with the noise to be measured by an observer facing the source and listening with both ears. When the reference tone is judged by a 'normal observer' to be as loud as the noise, the equivalent loudness in phons is given by the intensity level of the reference tone above a reference pressure of 0.0002 dyne per sq. cm. The experimental realization of the definition requires the resources of a laboratory, so that it becomes of interest to inquire how far the indications of portable secondary meters used for measurements in the field conform to the standard.

Many subjective secondary meters developed before the formulation of the standard, including one developed by us, operate by the observer listening simultaneously to the noise with one ear and a pure reference tone, presented by a telephone receiver, with the other. The reference tone is then adjusted by trial to loudness equality with the noise, the magnitude of which is expressed as the intensity of the reference tone in decibels above a stated reference intensity. In view of the disparity in listening conditions, it is important to ascertain whether the meter indications conform to the standard. We have carried out measurements, in accordance with the definition, of the equivalent loudness of noises of many types with a group of ten observers, such noises being also measured by the same group using a subjective meter of the type indicated above. It is found that with an instrument adjusted to read correctly for 1,000 cycle high-intensity tones, there are discrepancies of varying amounts up to $+15 \mathrm{db}$., depending upon the type of noise. For some purposes a correction of $-6 \mathrm{db}$. to the reading brings the indications sufficiently near to the standard.

A mode of listening approximating more to the definition is made possible by using a meter with two receivers. If suitable sealing is provided, the noise and reference tone may be heard alternately by quickly removing or replacing the receivers on the ears. The reference tone intensity is adjusted by trial until no loudness change is heard on removing or replacing the receivers. Tests with a meter constructed on these lines and calibrated in a 1,000 cycle free field show that for a variety of types of noise from 30 to 95 phons, the true value is given on an average to \pm 2.5 phons, the largest discrepancy in mean reading noted being 4 phons.
A meter of this type thus enables the measurement outside the laboratory of any type of steady noise in phons. It has been used for measuring the noise of large engineering plant and has been found more trustworthy than the single-telephone method. The two-telephone meter also forms a link between the plane field distribution of the phon definition and the irregular field distributions which may occur in practice. Such an irregular sound field is thereby assessed in terms of the intensity level of the 1,000 cycle plane wave which, for a 'normal observer', produces an equal loudness sensation. Thus the pronounced directional properties of some microphones, which may have an arbitrary effect in objective noise measurements, may be eliminated.

The performance of secondary meters in terms of the phon will be discussed in a paper which it is hoped to publish in the near future.
B. G. Churcher.

A. J. KrNG.

Research Department,

Metropolitan-Vickers Electrical Co., Ltd., Manchester, 17. July 18.

\section{Influence of Temperature on Crossing-over in Drosophila}

Although it has now been demonstrated by several workers that crossing-over in certain regions of the chromosomes of Drosophila melanogaster is affected by temperature, the experiment reported in Table 8 of Plough's classical paper ${ }^{1}$ still remains the only attempt to trace the magnitude of the effect throughout the range of temperature over which Drosophila is fertile. Unfortunately, when correcting the data for differences among the controls, a mistake was made which led to the false conclusion that crossingover showed two maxima, at $13^{\circ}$ and at $31^{\circ} \mathrm{C}$. The $b-p r-c$ region of chromosome II was used for the

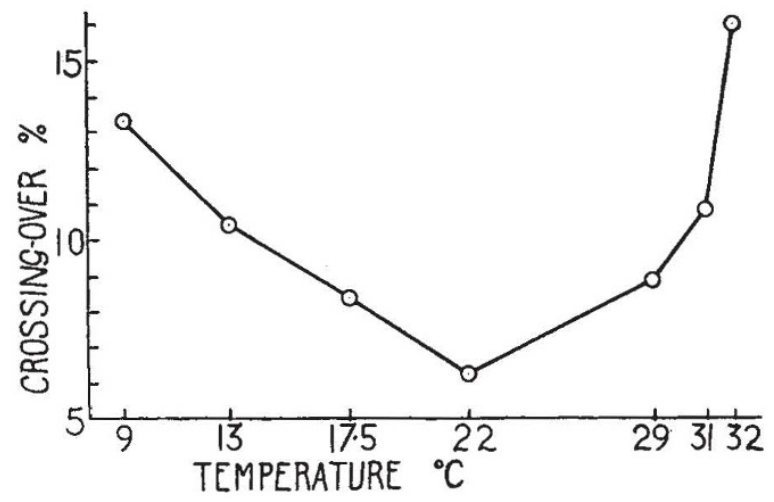

FIG. 1.

experiment. The observed percentages of crossingover between $b$ and $p r$ are reproduced in the table below:

Table 1.-Crossing-over between $b$ and $p r$. (Data from Plough's Table 8).

$\begin{array}{cccc}\text { Temperature } & \begin{array}{c}\text { Observed } \\ \text { per cent }\end{array} & \begin{array}{c}\text { Control } \\ \text { at } 22^{\circ} \mathrm{C} \text {. }\end{array} & \begin{array}{c}\text { Corrected values, that is, } \\ 6.0 \text { (Observed)/Control }\end{array}\end{array}$

$\begin{array}{rrrr}9 & 13 \cdot 5 & 6 \cdot 1 & 13 \cdot 3 \\ 13 & 13 \cdot 5 & 7 \cdot 8 & 10 \cdot 4 \\ 17 \cdot 5 & 8 \cdot 3 & 5 \cdot 9 & 8 \cdot 4 \\ 22 & 6 \cdot 0 & 7 \cdot 9 & 6 \cdot 0 \\ 29 & 8 \cdot 8 & 5 \cdot 9 & 8 \cdot 9 \\ 31 & 14 \cdot 0 & 7 \cdot 8 & 10 \cdot 8 \\ 32 & 15 \cdot 7 & 5 \cdot 9 & 16 \cdot 0\end{array}$

